\title{
EDITORIAL
}

\section{JJ Wyndaele ISCOS President}

Spinal Cord (2015) 53, 2; doi:10.1038/sc.2014.231
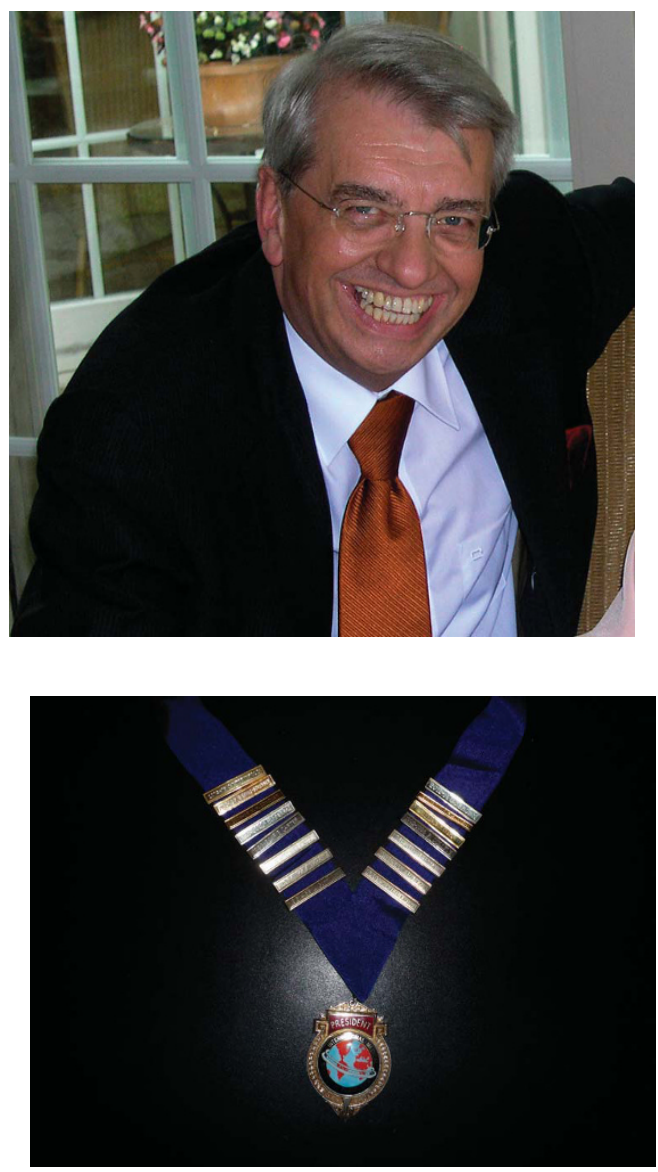

As many of you probably know I became the president of ISCOS after the AGM in Maastricht this year.

I want to use this space to describe what is going to be my policy.

First, some reflections on what lay behind us: Seventy years ago the great majority of spinal cord lesioned (SCL) died fairly quickly from their complications. Now many survive and the life expectation has reached almost normal levels. What has been a critical breakthrough? The two World Wars with their enormous numbers of SCI patients. Proper management was asked in 1919. It took more than 30 years before the management following these principles got going in the US, England and Canada with pioneers as Munro, Bors, Guttmann, Abrahamson, Davis, Freeman, Jousse and Talbot. A few years later Houssa, Tricot, Grossiord, Benassy, Frankel, Bedbrook, Dollfus and many others followed. In the last decades of the twentieth century the world has seen a real growth of interest with the creation of specialized centres in most countries of the world, an evolution that is not over yet. Many names of pioneers in their own right could be mentioned here.
The techniques used in spinal cord medicine are based not only on an increasing knowledge but also, for a big part, on common sense, attention for detail, perseverance and good will. One major point of attention today is the continuous research on restoration of the spinal cord and nerves, in order not to rehabilitate but to cure. We are not there as yet, but have to watch with great attention.

How did I get involved in SCL care? In 1976, I was asked to replace the senior staff member for weekly consultations in the SCL Centre in the University Hospital Ghent. I appreciated the general and comprehensive approach and continued learning in this field. It was so different then with a hospitalization for months and items as sexuality after handicap still being an uneasy item to bring up in consultations or group discussions. Being a urologist by training made me start in this part of SCL care but gradually I got interested in all aspects. My visit to Stoke Mandeville Hospital in 1977, to study 'non touch catheterization' gave the real breakthrough. I got to know ISCOS (IMSOP at that time) and its meetings, and found a real professional home and groups of people becoming friends.

Meanwhile my academic career progressed and after becoming medical doctor, research on catheterization in acute SCL care brought me a Doctorate in Biomedical Sciences. Later research during many years on sensory innervation in the viscera led to a $\mathrm{PhD}$. As full-time ordinary Professor at the University in Antwerp and Chair in my department the SCL-related work continued with consultancies in CTR Brussels and Revarte Antwerp. More than 300 publications were written by our group and 13 people defended their $\mathrm{PhD}$ under my guidance. The 'teach the teachers' projects in South East Asia have helped put my practice into perspective for more than 10 years.

ISCOS was and is my favourite scientific society. I have been a Council Member, Vice President, Honorary Secretary, President Elect and now the President. For the last 5 years I have served as the Editor-in-Chief of Spinal Cord journal. ISCOS is a family.

I have the privilege of having worked with many great names in SCL care from around the world, some of them were past presidents of ISCOS. I see ISCOS changing in the 21 st century but this process will have to be intensified and questions that remain so far have to be answered. With the executive and the different committees we will work on this so that ISCOS can be the worldwide umbrella organization where all involved in SCL management as well as consumers feel at home. Allied professionals organized in networks for nurses, PT, OT and others are welcomed in the group. Modern means of communication have created unseen possibilities. Relations with WHO are at a good level. We have to implement what we think is mandatory of all opportunities that present themselves in different aspects of modern life. This may seem very ambitious and it is ambitious but I am convinced that all together we can achieve a lot.

You know my email, so do not hesitate to contact me and tell what you want to do and what you hope for.

Wyndaelejj@skynet.be; Admin@iscos.org.uk; Spinalcord@uza.be.

JJ Wyndaele E-mail: Wyndaelejj@skynet.be 